\title{
Perancangan sistem informasi peserta kursus mengemudi berbasis web pada kursus mengemudi Ar'Rahman Jakarta
}

\author{
Fitriyani Hidayah $^{1}$, Rumadi Hartawan ${ }^{2}$, Zulhalim $^{3}$,Asih Septia Rini ${ }^{4}$ \\ Program Studi Sistem Informasi ${ }^{1}$, Program Studi Teknik Informatika ${ }^{2}$, Program Studi Teknik Informatika ${ }^{3}$, \\ Program Studi Manajemen ${ }^{4}$ \\ Sekolah Tinggi Manajemen Informatika dan Komputer Jayakarta ${ }^{123}$ \\ Sekolah Tinggi Ilmu Ekonomi Jayakarta ${ }^{4}$ \\ 19567005@stmik.jayakarta.ac.id,rumadi_hartawan@stmik.jayakarta.ac.id, zulhalim@gmail.com, \\ asihseptiarini06@gmail.com
}

\begin{abstract}
ABSTRAK
Perkembangan dunia internet sekarang ini sangat pesat telah menuntut banyak orang untuk memanfaatkan dunia maya dalam setiap kegiatan di dunia nyata, situs website dan internet merupakan media penyampaian informasi atau sebagai media pelayanan yang efektif dan efisien, dengan jaringan internet kita dapat menjelajah tanpa batas ruang waktu menggunakan jaringan internet. Sistem Informasi Komputerisasi berperan penting dalam segala bidang, misalnya dalam informasi pelayanan suatu lembaga, sistem komputerisasi ini bertujuan untuk mengelola data secara mudah, cepat, dan akurat. Selain itu harus didukung pula oleh sumber daya yang bermutu, yang dapat mengelola data dengan baik. Namun kenyataannya masih banyak lembaga kursus yang masih menggunakan sistem manual, seperti yang penulis temukan pada saat riset di Lembaga Kursus Mengemudi Ar'rahman Jakarta dalam mengelola data pendaftaran peserta kursus baru. Sehingga menjadi kurang efektif dan menumpuknya kertas-kertas dokumen peserta, serta lambatnya proses pembuatan laporan. Namun apabila proses tersebut diperbaharui menjadi suatu sistem yang terkomputerisasi maka akan menjadi jauh lebih baik. Untuk itulah penulis mencoba membuat perancangan mengenai Perancangan Sistem Informasi Peserta Kursus Mengemudi Ar'Rahman Jakarta. Untuk mencapai tujuan tersebut, penulis melakukan analisa sistem lebih mendalam dengan cara obsevasi dan wawancara secara mendetail kepada staff untuk selanjutnya penulis kelola dan paparkan. Dengan memanfaatkan perkembangan teknologi berbasis website ini diharapkan dapat membantu dan meningkatkan pelayanan yang lebih efektif, melakukan penyimpanan dokumen melalui database sistem agar tidak penumpukan arsip yang menyebabkan rusak atau hilang. Perancangan sistem informasi ini merupakan solusi terbaik untuk memecahkan permasalahan yang ada, serta dengan sistem yang terkomputerisasi dapat tercapai suatu kegiatan yang efektif dan efisien serta dapat lebih kondusif dibandingkan dengan sistem yang terdahulu.
\end{abstract}

Kata Kunci: Perancangan Sistem, Waterfall, Pendaftaran Kursus.

\begin{abstract}
The development of the internet today is very fast, it has demanded many people to take advantage of the virtual world in every activity in the real world, websites and the internet are media for delivering information or as an effective and efficient service medium, with the internet network we can browse indefinitely using space and time. Internet Network. Computerized Information Systems play an important role in all fields, for example in the service information of an institution, this computerized system aims to manage data easily, quickly, and accurately. In addition, it must also be supported by quality resources who can manage data well. However, in reality there are still many course institutions that still use the manual system, as the author found during research at the Ar'rahman Driving Course Institute Jakarta in managing registration data for new course participants. So that it becomes ineffective, efficient and the accumulation of participant documents and the slow process of making reports. However, if the process is updated into a computerized system it will be much better. For this reason, the author tries to make a design regarding the Design of Information Systems for Participants in the Ar'Rahman Jakarta Driving Course. To achieve this goal, the authors conducted a more indepth system analysis by means of observation and detailed interviews with staff for further management and explanation. By utilizing the development of website-based technology, it is hoped that it can help and improve services that are more effective, storing documents through the system database so that there is no accumulation
\end{abstract}

Ciptaan disebarluaskan di bawah Lisensi Creative Commons Atribusi 4.0 Internasional.

http://journal.stmikjayakarta.ac.id/index.php/JMIJayakarta 
DOI: $10.52362 / j m i j a y a k a r t a . v 1 i 1.416$

of archives that cause damage or loss. The design of this information system is the best solution to solve existing problems, and with a computerized system, an activity that is effective and efficient can be achieved and can be more conducive than the previous system.

Keywords: System Design, Waterfall, Course Registration.

\section{PENDAHULUAN}

\section{Permasalahan}

Sistem penerimaan peserta kursus mengemudi selama ini yang penulis ketahui masih menggunakan metode manual, baik dalam pencatatan data pendaftar, penjadwalan maupun pengarsipan, sehingga menimbulkan kendala saat pendataan atau pencarian data peserta, ketika pihak admin ingin mencari salah satu data dari peserta kursus mengemudi akan menjadi lama, karena harus membuka catatan peserta kursus mengemudi kembali, hal ini mengakibatkan tidak maksimalnya dalam pelayanan dan sangat memungkinkan kehilangan data peserta kursus mengemudi.

\section{Teori Terkait}

\section{Website}

1. Rancangan Website

a. Internet

Menurut Krisianto (2014:1) dalam jurnal (Puspitasari, 2015:187) Internet adalah salah satu bentuk media komunikasi dan informasi interaktif. wujud internet adalah jaringan komputer yang terhubung di seluruh dunia. Internet digunakan untuk mengirim informasi antar komputer di seluruh dunia. Internet diartikan sebagai "The global public Transmission Control Protocol/Internet Protocol (TCP/IP) internetwork". Jadi Internet adalah gabungan

dari seluruh komputer didunia yang di satukan oleh sebuah "bahasa" yang sama, adapun bahasa yang dimaksud adalah Transmission Control Protokol/Internet Protokol (TCP/IP).

b. Web Server

Menurut Jurnal Achamad Solichin (2016:7) Web server merupakan sebuah perangkat lunak dalam server yang berfungsi menerima permintaan (request) berupa halaman web melalui HTTP atau HTTPS dari klien yang di kenal dengan browser web dan mengirimkan kembali (response) hasilnya dalam bentuk halam halaman web yang umunya berbentuk dokumen HTML.

c. Web Browser

Menurut Sholechul Azis (2013:19) Perambah web (bahasa inggris:web browser), disebut juga sebagai perambah, adalah perangkat lunak yang berfungsi menampilkan dan melakukan interaksi dengan dokumendokumen yang disediakan oleh server web.

\section{METODE DAN MATERI}

\section{Kerangka Pemikiran}

Pengelolaan data peserta sebaiknya mampu menyajikan data disposisi elektronik secara real time sehingga mampu meningkatkan kinerja pegawai dan mempercepat tecapainya tujuan organisasi. Peneliti memberikan usulan untuk membuat sistem informasi data peserta yang bisa diakses oleh seluruh pegawai berikut fasilitas pemberian disposisi langsung pada aplikasi yang diharapkan akan mampu mengatasi masalah yang terjadi saat ini agar bisa meningkatkan efektifitas dalam bekerja baik bagi pegawai maupun pimpinan dalam mencapai tujuan sesuai tugas pokok dan fungsi organisasi.

\section{Model Pengembangan Perangkat Lunak}

Dalam buku Sukamto dan Shalahuddin (2015:28) menjelaskan bahwa model SDLC air terjun (Waterfall) sering juga disebut model sekuensial linier (Sequential Linear) atau alur hidup klasik (Classic Life Cycle)". Model air terjun menyediakan pendekatan alur hidup perangkat lunak secara sekuensial atau terurut dimulai dari analisis, desain, pengodean, pengujian dan tahap pendukung.

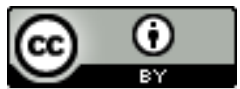




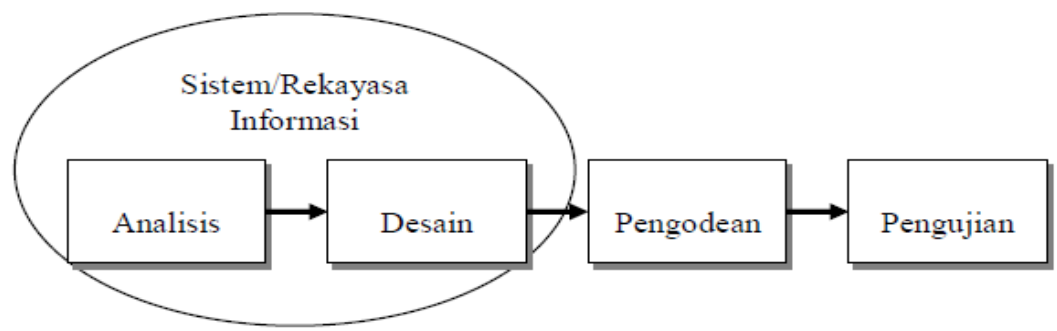

Sumber : Rossa. A S dan M. Shalahuddin (2015:29) Ilustrasi Model Waterfall

Menurut Rossa. A. S dan Shalahuddin (2015:29), Model SDLC air terjun (waterfall) sering juga disebut model sekuensial linear (sequential linear) atau alur hidup klasik (classic life cycle). Model air terjun menyediakan pendekatan alur hidup perangkat lunak secara sekuensial atau terurut dimulai dari analisis, desain, pengodean, pengujian, dan tahap pendukung (support). Berikut adalah gambaran air terjun:

1. Analisa kebutuhan perangkat lunak

Proses pengumpulan kebutuhan dilakukan secara intensif untuk menspesifikasikan kebutuhan perangkat lunak agar dapat dipahami perangkat lunak seperti apa yang dibutuhkan oleh pengguna. Spesifikasi kebutuhan perangkat lunak pada tahap ini perlu untuk didokumtentasikan.

2. Desain

Desain perangkat lunak adalah proses multi langkah yang fokus pada desain pembuatan program perangkat lunak termasuk struktur data, arsitektur perangkat lunak, representasi antar muka, dan prosedur pengodean. Tahap ini mentranslasi kebutuhan perangkat lunak dari tahap analisis kebutuhan ke representasi desain agar dapat diimplementasikan menjadi program pada tahap selanjutnya. Desain perangkat lunak yang dihasilkan pada tahap ini juga perlu didokumentasikan.

3. Pembuatan kode program

Desain harus ditranslasikan kedalam program perangkat lunak. Hasil tahap ini adalah program komputer sesuai dengan desain yang telah dibuat pada tahap desain.

4. Pengujian

Pengujian fokus pada perangkat lunak secara logis dan fungsional dan memastikan bahwa semua bagian sudah teruji. Hal ini dilakukan untuk meminimalisir kesalahan dan memastikan keluaran yang dihasilkan sesuai dengan yang diinginkan.

5. Pendukung

Tidak menutup kemungkinan sebuah perangkat lunak mengalami perubahan ketika sudah dikirim ke user. Perubahan bisa terjadi karena adanya kesalahan yang muncul dan tidak terdeteksi saat pengujian atau perangkat lunak harus beradaptasi dengan lingkungan baru. Tahap pendukung atau pemeliharaan dapat mengulangi proses pengembangan mulai dari analisis spesifikasi untuk perubahan perangkat lunak yang sudah ada, tapi tidak untuk membuat perangkat lunak baru.

\section{PEMBAHASA DAN HASIL}

1. Analisis Data

Di dalam tahap analisis ini ada beberapa langkah yang penulis lakukan. Adapun langkah-langkah tersebut adalah sebagai berikut :

a. Penulis menganalisa alur proses sistem pendaftaran yang berjalan di Sekolah Mengemudi Ar'rahman Jakarta dari calon peserta kusrus datang dan mengisi formulir sampai terdaftar sebagai peserta kursus di Sekolah Mengemudi Ar'rahman Jakarta.

b. Penulis menganalisa keadaan sistem pendaftaran yang sedang berjalan, Penulis pun menggambarkan prosedur sistem yang sedang berjalan pada Sekolah Mengemudi Ar'rahman Jakarta tersebut.

c. Mengidentifikasi masalah dan kelemahan sistem yang sedang berjalan. Dengan diketahuinya masalah dan kelemahan sistem yang sedang berjalan diharapkan pengembangan sistem yang baru dapat membantu mengurangi masalah dan kekurangan yang ada. 


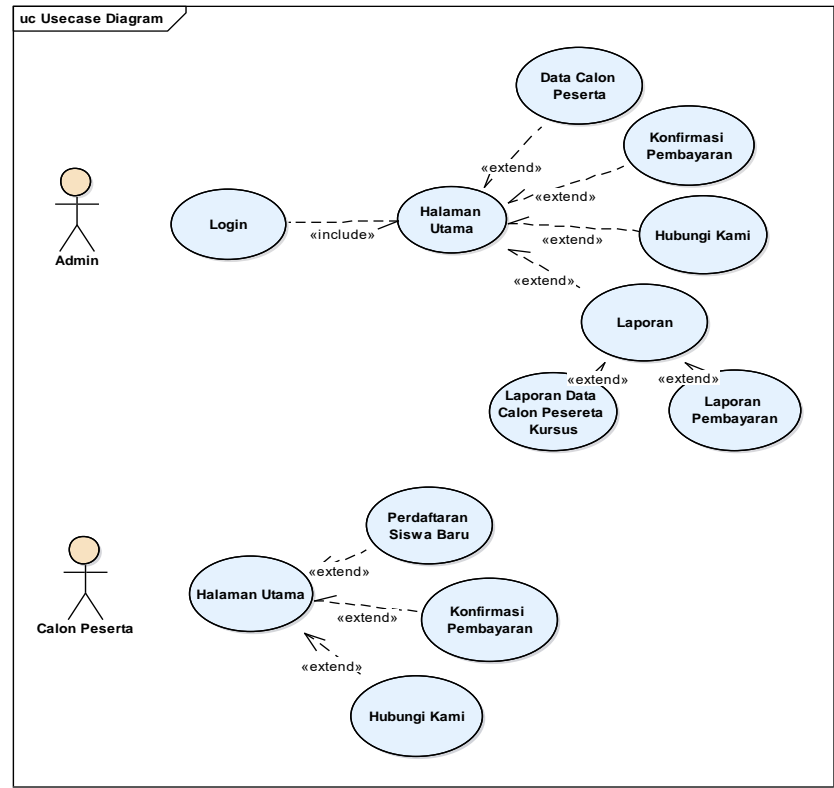

Use Cace Informasi Penerimaan Peserta Kursus

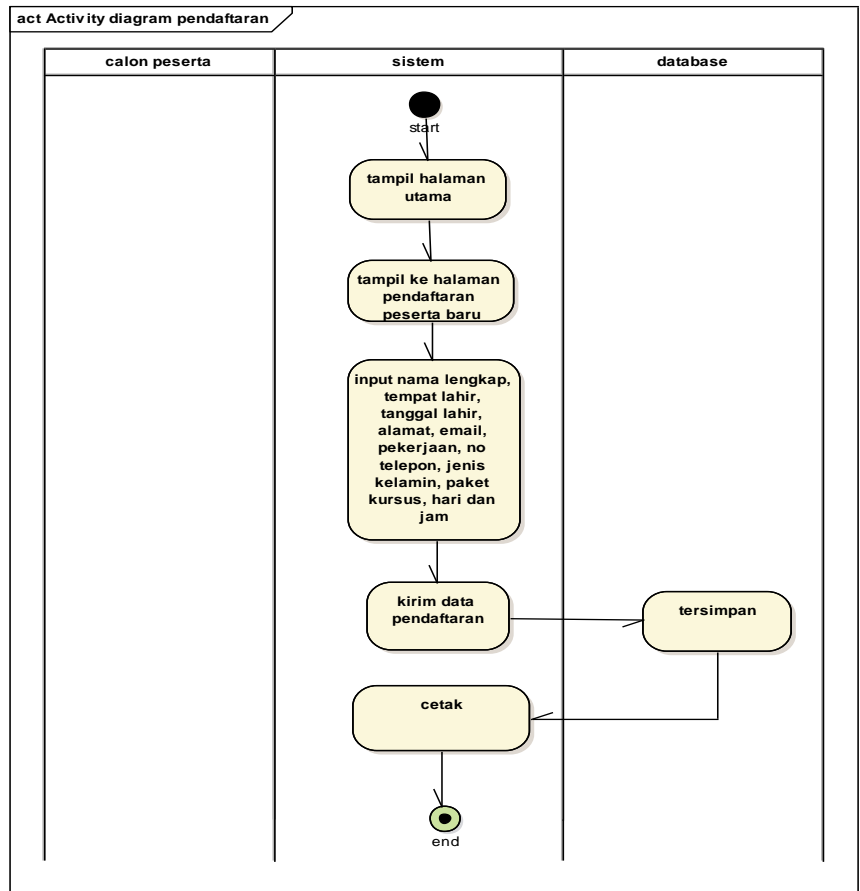

Sistem Pendaftaran

\section{KESIMPULAN}

Dengan adanya sistem pendaftaran yang terkomputerisasi ini, maka akan mempermudah calon peserta kursus mengemudi dalam melakukan pendaftaran melalui web. 


\section{REFERENASI}

[1] Krisianto (2014:1) dalam jurnal (Puspitasari, 2015:187)

[2] Achamad Solichin (2016:7) Pemrograman Web dengan PHP dan MySQL

[3] Sholechul Azis (2013:19) Web Personal, Organisasi dan Komersil

[4] Rossa. A. S dan Shalahuddin (2015:29), Rekayasa Perangkat Lunak

[5] Anggeri S. Nurjaman dan Verdi Yasin (2020) "Konsep desain aplikasi sistem manajemen kepegawaian berbasis web pada PT. bintang komunikasi utama (Application design concept of web-based staffing management system at PT Bintang Komunikasi Utama)", Journal of Information System, Informatics and Computing, Volume 4 Nomor 2 (2020) p143-174, diterbitkan tanggal 28 Desember 2020. http://journal.stmikjayakarta.ac.id/index.php/jisicom/article/view/363

[6] Ito Riris Immasari dan Verdi Yasin (2019) "Penggunaan metode analytic hierarchy process untuk menganalisis faktor-faktor yang mempengaruhi pemilihan calon legislatif di dprd ii kota tangerang", Journal of Information System, Informatics and Computing, Volume 3 Nomor 2 (2019) p53-58, diterbitkan tanggal 11 Desember 2019) .

http://journal.stmikjayakarta.ac.id/index.php/jisicom/article/view/139

[7] Badri Zaki dan Syahrizal Dwi Putra (2018) "Aplikasi bengkel online menggunakan global positioning system (gps) berbasis android pada CV. Rumah Otomotif”, Journal of Information System, Informatics and Computing, Volume 2 Nomor 2 (2018) p16-25, diterbitkan tanggal 31 Desember 2018). http://journal.stmikjayakarta.ac.id/index.php/jisicom/article/view/64 